\title{
Coloquio «Trabajo infantil y estrategias familiares en América Latina»
}

\section{Robin Cavagnoud}

\section{OpenEdition}

Journals

\section{Edición electrónica}

URL: http://journals.openedition.org/bifea/4006

DOI: $10.4000 /$ bifea.4006

ISSN: 2076-5827

\section{Editor}

Institut Français d'Études Andines

\section{Edición impresa}

Fecha de publicación: 1 agosto 2007

Paginación: 314-315

ISSN: 0303-7495

\section{Referencia electrónica}

Robin Cavagnoud, «Coloquio «Trabajo infantil y estrategias familiares en América Latina» », Bulletin de I'Institut français d'études andines [En línea], 36 (2) | 2007, Publicado el 01 febrero 2008, consultado el 01 diciembre 2020. URL : http://journals.openedition.org/bifea/4006 ; DOI : https://doi.org/10.4000/ bifea.4006

\section{(2) $(\mathcal{Q} \Theta \Theta$}

Les contenus du Bulletin de l'Institut français d'études andines sont mis à disposition selon les termes de la licence Creative Commons Attribution - Pas d'Utilisation Commerciale - Pas de Modification 4.0 International. 


\section{COLOQUIO «TRABAJO INFANTIL Y ESTRATEGIAS FAMILIARES EN AMÉRICA LATINA»}

Lima, 18-19 de julio de 2007

Este coloquio organizado en colaboración entre el Instituto Francés de Estudios Andinos (IFEA) y la Pontificia Universidad Católica del Perú (PUCP) tuvo lugar los 18 y 19 de julio de 2007 en Lima. Este evento se abrió a varias disciplinas de ciencias sociales (sociología, demografía, antropología, economía) y humanas (educación, psicología) y contó con la presencia de la Dra. María Eugenia Cosio Zavala, directora del Centro de Investigación y de Documentación de América Latina de París. El objeto de este coloquio fue explorar las estrategias familiares en América Latina como fenómeno mayor de la realidad social de los países de este continente. En este marco de reflexión, los exponentes privilegiaron la problemática del trabajo infantil y adolescente pero también fueron profundizadas otras formas de acción realizada por uno o varios miembros de una familia para tratar de mejorar las condiciones de vida de la unidad doméstica (en particular las ponencias de Jeanine Anderson y de Camille Boutron). Las ponencias se enfocaron esencialmente en estudios de caso referidos a las situaciones en el Perú y México.

Alejandro Cussianovich abrió este coloquio con una presentación sobre los temas de la infancia y del trabajo en los países del Sur, poniendo énfasis en los esfuerzos de las culturas del «Sur» para llegar a un reconocimiento no solo en el campo de la infancia trabajadora sino también en otros campos de reflexión y desembocar en una revisión de la actual división internacional del poder y del saber. Luego Jeanine Anderson presentó el desarrollo de un trabajo de campo de varios años en la zona urbana de Pamplona Alta ubicada en el Cono Sur de Lima sobre la transformación de las formas de pobreza reproducidas a través de tres generaciones de mujeres («madres, hijas y nietas»). Robin Cavagnoud hizo luego una exposición detallada de un trabajo de campo personal realizado con cincuenta adolescentes trabajadores de Lima. Este estudio cualitativo le permitió llegar a una primera reflexión novedosa sobre la clasificación del trabajo adolescente en zonas urbanas en base a la finalidad que los mismos adolescentes dan de su actividad económica. Esta ponencia permitió una aclaración del fenómeno muy heterogéneo del trabajo infantil en Lima. Por fín, la primera tarde de trabajo se acabó con una ponencia de María Eugenia Cosio Zavala sobre las trayectorias familiares y profesionales de los niños en México en base a la encuesta biográfica nacional EDER realizada en 1998. Esta presentación dio un panorama muy interesante en cuanto a la evolución de la sociedad mejicana a lo largo del siglo XX.

En la segunda tarde de trabajo, Silvana Vargas y José Rodríguez empezaron con la presentación de un estudio realizado sobre el uso del tiempo social entre escuela y trabajo de parte de los niños, niñas y adolescentes trabajadores en Lima enfocándose en la teoría del capital humano. Esta ponencia demostró el carácter esencial de los factores familiares en la asignación del tiempo social de los niños, niñas y adolescentes. A continuación, Luis García Núñez presentó con un enfoque económico su trabajo de tesis doctoral sobre el trabajo infantil extra familiar y el trabajo en quehaceres del hogar en base a las Encuestas de Niveles de Vida (ENNIV), analizando entre otros la relación entre el grado de pobreza y la probabilidad de un niño o adolescente a entrar en el mundo laboral. Luego, Leigh Campoamor expuso su trabajo de campo etnológico actual con niños trabajadores de Lima, presentando con muchos detalles las historias de vida de niños y adolescentes a quienes ella misma acompaña en su vida cotidiana en las calles de Lima. Esta ponencia analizó la actuación social de los niños, niñas y adolescentes trabajadores dentro de la estructuras de la sociedad peruana y la búsqueda de legitimación de su propia identidad y derechos. Camille Boutron siguió con una exposición sobre la problemática de la esfera privada como elemento de reconciliación y de reintegración social para las ex combatientes del conflicto armado interno peruano. Esta ponencia demostró que la familia es un elemento esencial de ayuda para las mujeres que salen de la cárcel como forma de garantía social frente a su invisibilidad y en su dinámica de reconstrucción del vínculo social. Por fin, Aldo Valencia Piñan presentó las actividades de la Casa de Panchita con niñas y adolescentes empleadas en trabajos domésticos en Pamplona Alta explicando varios aspectos del funcionamiento de la economía popular en zonas urbanas marginales de Lima. 
Los elementos teóricos de síntesis que podemos sacar de la serie de ponencias de este coloquio son los siguientes. Las decisiones tomadas por cada uno de los miembros de una familia (padre, madre, hijos, hijas, abuelos, nietos) en la organización y elaboración del cotidiano tienen una importancia fundamental, particularmente en un contexto de fuertes coacciones económicas o a raíz de una situación de exclusión social. Cada familia en su funcionamiento diario se encuentra vinculada con las coacciones y recursos no solo de sus condiciones materiales sino también de su universo social: sistema de representaciones y valores, formas de organización social, relaciones de poder, entre otros. Las familias obedecen a las exigencias y limitaciones que les impone este contexto social y material (tanto en zonas urbanas como rurales) pero cada miembro, incluyendo a los niños, niñas y adolescentes, conservan como actores económicos un margen de maniobra que les permite actuar como sujetos de su propia existencia y de la de su unidad familiar al mismo tiempo. Esta capacidad de interpretación de los hechos y de acción en la organización del cotidiano y de la sobrevivencia familiar se concreta generalmente en la concertación entre los diferentes miembros del hogar y muestra una dimensión estratégica evidente. Este margen de maniobra que se refleja en una serie de elecciones es tanto limitada como suficientemente operante para enfrentar, al menos parcialmente, los factores de riesgo y de vulnerabilidad del medio social. Las familias sometidas a condiciones de pobreza deben luchar permanente y diferentemente cada una para asegurar su existencia material, romper la amenaza del aislamiento social y afectivo, y conservar de ellas mismas una imagen valorizada.

\section{Robin CAVAGNOUD}

